\title{
Sealant Matrix Dosage Form
}

National Cancer Institute

\section{Source}

National Cancer Institute. Sealant Matrix Dosage Form. NCI Thesaurus. Code C149893.

Solid sterile preparation consisting of a pliable piece of material impregnated or coated with a sealant or with a powder that forms a sealant after contact with an appropriate fluid (e.g. blood). It may act as a hemostatic agent and/or tissue glue. The matrix may itself form part of the seal, and is usually absorbed by the body over time. 